\title{
Ni aristócratas, ni rebeldes, ni tristes ni contentos: Escritura y Revistas Literarias de Joaquín Edwards Bello, Teresa Wilms Montt y Vicente Huidobro*
}

\author{
Marina d. A. Alvarado Cornejo ${ }^{* *}$
}

\section{Resumen}

Este trabajo tiene por objetivo problematizar la producción escritural de Joaquín Edwards Bello (1887-1968), Vicente Huidobro (1893-1948), y dar a conocer el ingreso al campo literario de Teresa Wilms Montt (1893-1921) a través de las revistas literarias. Estos autores no sólo tienen en común haber compartido el mismo marco epocal, sino también su proveniencia social aristócrata, de buen talante económico y relacional, lo que desde su cuna les hacía pertenecer al campo de poder, lo cual les restaba autonomía frente a la elección y desarrollo de sus capitales específicos (Bourdieu, 2005). No obstante su acomodada disposición, estos escritores, particularmente Edwards Bello y Huidobro, se transformaron en productores heréticos, en tanto discutieron contra sus familias y las instituciones dominantes. Esto último se analizará desde la redefinición de la revista literaria en tanto constructora del campo y espacio de pugna de posiciones de donde participaron estos tres autores, donde desconfiguraron sus habitus.

Palabras clave: Joaquín Edwards Bello, Teresa Wilms Montt, Vicente Huidobro, revistas literarias.

\begin{abstract}
This paper aims to problematize the literary production of Joaquín Edwards Bello (18871968), Vicente Huidobro (1893-1948), bring to light the entrance to the literary field of Teresa Wilms Montt (1893-1921), through literary magazines. These authors have in common to have shared not only the same historical framework, but also their good economic and relational educational situation due to their aristocratic and social background, so, their shared cradle made them belong to the field of power, wich reduced their autonomy from the election and development of their specific capital (Bourdieu, 2005). Despite their affluence, these writers, particularly Edwards Bello and Huidobro, became heretical producers as they criticize their families and dominant institutions. The latter will be analyzed from the redefinition of the literary magazine as builder of the field and space of conflicting positions from where these three authors participated and deconfigured their habitus.
\end{abstract}

Key words: Joaquín Edwards Bello, Teresa Wilms Montt, Vicente Huidobro, literary magazines.

* Este artículo es parte de mi tesis doctoral de Literatura, dedicada al estudio de las revistas literarias modernistas y vanguardistas chilenas.

* Dra. (C) en Literatura, Pontificia Universidad Católica de Valparaíso. Profesora Adjunta de la Universidad Católica Cardenal Silva Henríquez. Correo electrónico: alvarado.marina@gmail.com 


\section{Introducción}

En la carta inédita que Joaquín Edwards Bello (1887-1968) envió a Vicente Huidobro (1893-1948) el año 1922, período en el cual los primos políticos se hallaban en Europa, Edwards manifestó lo siguiente:

Ud. y yo pertenecemos a la clase alta chilena y cuatro majaderos dijeron que en esa clase no puede existir talento.

Nosotros hemos hecho el Milagro. Naciendo cerca del Club de la Unión, que es el punto más absurdo del planeta, tenemos talento.

(Edwards Bello, 1922: s/p)

Esta cita da cuenta de un cambio de paradigma sociocultural que afecta a los hijos de los otrora señores aristócratas, herederos naturales de la política, economía y cultura, en definitiva, de las disposiciones privilegiadas dentro del campo del poder ${ }^{1}$. Por otra parte, muestra que el habitus, definido por Pierre Bourdieu (2005) como el sistema de disposiciones moldeado por las estructuras sociales, es decir, la subjetividad socializada que reproduce los condicionamientos sociales pero que a su vez puede ser cambiado, para Edwards Bello, Wilms Montt y Huidobro, es centro de contradicciones existenciales y estéticas, a su vez que motor nutricio para la serie de estrategias textuales y discursivas que despliegan para escribir su propia trayectoria dentro del campo literario, donde destacamos la producción y participación de revistas literarias en los primeros veinte años del siglo XX.

1 Pierre Bourdieu (2005) define el campo como "una red de relaciones objetivas (de dominación o subordinación, complementariedad o antagonismo, etc.) entre posiciones". (342) Dentro de este entramado, los sujetos, acorde a su habitus, gozan de una cierta disposición, la cual está objetivamente definida por el sistema de propiedades pertinentes, que permiten situarla en relación con todas las demás en la estructura de la distribución global de las propiedades. Siguiendo a P. Bourdieu, "todas las posiciones dependen, en su existencia misma, y en las determinaciones que imponen a sus ocupantes, de su situación actual y potencial en la estructura del campo, es decir, en la estructura del reparto de las especies de capital (o de poder) cuya posesión controla la obtención de beneficios específicos (como el prestigio literario) que están puestos en juego en el campo." (342). Sin embargo, los y las sujetos tienen la posibilidad de discutir su habitus, es decir, su disposición en el universo de tomas de posición, espacio poco institucionalizado, como el campo literario o artístico, donde sólo se dejan aprehender a través de las obras literarias o artísticas, las que se entienden como el capital simbólico construido por quienes están disputando posiciones. 
La producción literaria de los escritores recién mencionados tuvo por escenario temporal la primera década del siglo XX, caracterizada por Bernardo Subercaseaux como un período en que "asistimos a un nuevo y activo proceso de construcción intelectual y simbólica de la nación, que se expresa a través de distintas prácticas discursivas (los rituales de celebración del Centenario, la literatura de la crisis, la crónica periodística, las memorias o libros de viaje)." (12). Las diferentes expresiones escriturales surgidas entre 1900 y 1910 buscaron reformular los cánones culturales en una sociedad que sufría el quiebre de las costumbres coloniales- tradicionales por causa de la emergencia de nuevos actores socioculturales. Entre los nuevos sujetos se cuentan: los estudiantes, los obreros, los bohemios, los intelectuales y las mujeres, quienes, hacia la segunda década del siglo, ya eran parte del campo social, cultural y, específicamente, del literario, en tanto que habían construido bienes simbólicos que les permitieron disputar disposiciones dentro de éste. A este proceso, Grínor Rojo (2004) lo denomina "segunda transformación de una modernidad que comprende las décadas de 1920 a 1950, [...] período altamente significativo pues en él se hace evidente la presencia de voces portadoras de visiones alternativas a los discursos oficiales." (10).

Bajo este marco, en este trabajo estudiaremos el trayecto discursivo desarrollado por Joaquín Edwards Bello y Vicente Huidobro en las revistas literarias fundadas y dirigidas por ellos durante las primeras dos décadas del siglo XX, en tanto que a Teresa Wilms Montt la integramos dentro de los autores revisados, pues no sólo comparte época y amistad con ambos escritores, sino también porque su producción literaria fue publicitada en Buenos Aires a través de la revista Nosotros.

\section{2. $\mathrm{Ni}$ aristócratas ni rebeldes}

Joaquín Edwards Bello, Teresa Wilms y Vicente Huidobro son los intelectuales rebeldes y cosmopolitas que se abrieron a las nuevas estéticas europeas, principalmente en el caso del autor de Altazor (1925). Edwards Bello, por su parte, desarrolló un periodismo desenfadado y desmitificador. Finalmente, los tres autores hicieron de su propia vida un manifiesto, concibiéndola como una obra de arte, al extremo que las contradicciones que intentan subsanar con su escritura se confunden y se disfrazan con su propia biografía, como es el caso paradigmático de Teresa Wilms. Sobre esto mismo, no podemos olvidar lo que plantea Jacques Dubois (1988), para quien "todo texto ficcional es una figuración de la manera en que su autor se sitúa, toma posición, ideal o prácticamente, en el espacio institucional" (49).

El campo literario, más autonomizado hacia la época del Centenario, ha trocado sus reglas estructurales, pues los ostentadores del poder no son quienes recuerdan al "intelectual-político-letrado" a la usanza de Bello, Lastarria o Bilbao, 
sino que son quienes gozan de un menor capital simbólico², pero un mayor capital específico, lo que, por cierto, está ligado a los productores autónomos y no a los heterónomos ${ }^{3}$. Esta situación es producto de la emergencia de nuevos sujetos dentro del ámbito social: las mujeres, los obreros, los estudiantes, los anarquistas, los profesionales de la letras, lo que está aparejado, según el Diccionario de movimientos y grupos literarios chilenos (1993), con "el declive de la aristocracia europeizante y el avance de los sectores medios y obreros. Este cambio en la estructura social se percibe en el desplazamiento de la población rural hacia las ciudades, los puertos y las minas [...]" (154).

Según el párrafo anterior, entonces, no es difícil comprender el porqué del menosprecio y desconfianza que Joaquín, Teresa y Vicente inspiran, ya que, según las leyes específicas del campo, sólo triunfará en el ámbito simbólico quien pierda en el ámbito económico, es decir, quien se margine de la producción masiva hecha para el gran público. Sin embargo, si bien estos tres escritores pasaron "pellejerías", sobre todo cuando vivían en Europa, el apoyo permanente recibido de sus respectivas familias y los bienes heredados, les garantizaron libertad frente al "rey burgués". Esta situación la señaló Teresa Wilms en la entrevista que brindó a Sara Hübner Bezanilla en el año 1920 en París: "En España estuve un tiempo pobre, pero fui feliz. Había amigos, buenos camaradas, amor, sinceras simpatías.” (Hübner, S., 1993: 56)

Pero la buena situación familiar también se transformó en motivo de desprecio, como le cuenta Edwards Bello a Huidobro en esta segunda carta del año 1922: "Una vez, en una librería de Santiago, el librero extranjero me dijo que el arte nacional no valía nada, que todo era influencia y plagio de Francia. Que su madre de Ud. ${ }^{4}$ había comprado su fama en Europa. [...]" ${ }^{5}$

\section{Escritura y revistas literarias}

Este mal miramiento no fue un impedimento poderoso para evitar la entrada de estos escritores al campo literario, pues es allí donde se disputan las posiciones y donde se enlazan redes de relaciones que les permitirán, a la larga, posicionarse y rearmar su habitus.

2 El capital simbólico corresponde a todos aquellos bienes reconocidos por el campo de poder, en tanto el capital específico es ostentado por los productores heréticos, autónomos, es decir, quienes no producen bienes para el "gran mercado", sino que se identifican con la "producción pura”, aquella que es consumida y, por ende, comprendida, por los mismos productores, quienes no tienen expectativas monetarias.

3 Los productores autónomos son quienes carecen de capital económico y capital simbólico, pues no dependen de los productores heterónomos, es decir, de quienes elaboran bienes simbólicos desde el poder y en busca de recompensas económicas y no culturales o específicas (como es el caso de los autónomos).

4 La madre de Vicente García Huidobro Fernández era doña María Luisa Fernández, quien fundó la revista Musa Joven el año 1912, y de la cual su hijo poeta era el director. Ella participaba activamente en ella, en la sección de crítica cinematográfica, donde firmaba como "Monna Lissa".

5 El subrayado no es mío, sino que es original de la carta de Edwardas Bello. 
Es el caso prematuro de Joaquín Edwards Bello, quien en el año 1901, con sólo 14 años de edad y aún siendo alumno del colegio Mc Kay de Viña del Mar, fundó junto a Alberto Díaz la revista La Juventud, la cual logró cinco números de publicación (lo que para la época era bastante), y llevaba el siguiente epígrafe: "Periódico Literario Quincenal". Esta publicación reúne textos poéticos, periodísticos, particularmente crónicas, cuentos e impresiones ciudadanas. Su primer número apareció el domingo 17 de marzo y, a modo de columna editorial, se leía lo siguiente:

Al dar luz a esta modesta Revista, no nos mueve otro deseo, ni nos guía otro ideal que el de ofrecer a la juventud estudiosa un pequeño campo de ensayo.

No haremos promesas, que casi siempre resultan vanas: trabajaremos, sí, por despertar en los jóvenes el deseo de saber y distinguirse en el bellísimo, cuanto difícil arte del bien decir.

Quizá se tache de arriesgada nuestra empresa [...] Hoy (sic) entramos a la lid con el alma llena de ilusiones y el corazón de esperanzas [...]

(La Juventud, 1901:01)

Si bien esta revista adhiere a una línea estética naturalista y romántica, a la vez que no incorpora escrituras identificables como modernistas (menos el diseño del periódico), es una publicación que tiene conciencia de sí misma en tanto apertura de espacio de los posibles que, a la vez, ingresa a un campo de luchas donde la supervivencia no es sencilla.

Al año siguiente (1902), Edwards Bello fundó la revista El pololo, la cual llevaba el siguiente epígrafe: "Periódico de monos, monas y monadas, que dice muchas cosas y que no dice nada. Al que le pique...que se rasque". Esta publicación, en tanto al contenido y a la madurez escritural de J.E.B., quien por cierto estrena el seudónimo "Petit Report", fue un medio que no superó los tres números. Sin embargo, lo identificamos más próximo al proyecto literario de El Inútil, donde la estrategia que prima es la ironía y la polemización con los demás medios periodísticos existentes. Atendiendo a esto, citamos la nota editorial del número 3 de la revista titulado: "Devolvemos los <<saludos >>"

¡Qué frájil es la memoria humana!

Lo contestamos con franqueza, se nos había olvidado por completo contestar los cariñosos saludos que nos hicieron los colegas de la localidad cuando apareció nuestro primer número.

¡Ira de Dios! Y cómo te han puesto, pobre Pololo.

El Mercurio, el diario de los reporters-tortugas, que buscan las más sensacionales noticias andando a razón de una cuadra por hora [...]

La católica, la poderosa Unión, haciendo caso omiso de su religión que le ordena <<amar a su prójimo como a sí misma >> [...] El inofensivo Pololo, que pensaba pasar su vida zumbando alegre- 
mente en los espacios, adquirió de improviso ante sus colegas locales las enormes proporciones del águila gigantesca. [...]

La guerra está pues declarada.

El fuerte contra el débil, Goliat contra David.

(El Pololo, 1902: 02)

A partir de esta cita, notamos que el proyecto creador de Edwards se posiciona contrario a los medios conservadores, lejano de la escritura impresionista, pues el sujeto de la enunciación es crítico y, a su vez, tiene conciencia de libertad creadora "pura" (en términos de Bourdieu), contraria a los medios heterónomos cuya producción depende del mercado, es decir, de la "gran producción". 6 Por otra parte, no podemos dejar pasar el disgusto que le causa El Mercurio, medio fundado por su pariente lejano a quien simpáticamente llama "Cucho" (Agustín Edwards Ross).

La conciencia que demuestra el joven Edwards no es más que la autoconciencia de sí mismo y de su entorno, lo que lo lleva a despreciar a la sociedad que margina las aspiraciones literarias y libertarias, de modo que, en un futuro próximo, Joaquín afirmaría su condición "moderna" dedicándose al periodismo crítico, irónico y sagaz. Sin embargo, esto no quita que, como sujeto-escritor, no sufra de una inseguridad moral.

Pero no es sólo Edwards quien está publicando revistas literarias. En Chile, principalmente en Santiago, a partir del año 1894, hubo una eclosión de publicaciones dedicadas principalmente a la difusión de las letras y de los primeros autores profesionales que adherían al Modernismo, o bien, que aún reproducían la estética naturalista y romántica. Es el caso paradigmático de La Ley (1894), La revista cómica (1895), Lilas y Campanulas (1897), La Revista de Chile (1898), La Lira Chilena (1898), La Revista (1899), La Revista de Santiago (1899), El búcaro santiaguino (1899), La Ilustración (1899), Artes y Letras (1899), Las Letras (1900), Pluma y Lápiz (1900). En esta última, Joaquín Edwards Bello publicó en el año 1903 la narración humorística "La zapatilla homicida". Contamos también las revistas La Revista Nueva (1900), Instantáneas (1900), Luz i Sombra (1900), La Revista (1900), Instantáneas Luz y Sombra (1900), El pololo (1902), Ciencias i Letras (1902), entre otras. Las publicaciones que hemos mencionado se enmarcan en el período determinado por Naín Nómez (a.2000), como Primer y Segundo Modernismo. El primer momento surge a partir de la decantación de una propuesta poética emergente, "todavía empobrecida por la impureza de un lenguaje pluriforme que se produce con la estadía de Darío en Chile (18861889) [...] Lo que abre Azul, con una influencia difusa, pero que se decanta en

6 (Bourdieu, 2005, 186- 187) El campo literario unificado tiende a organizarse en función de dos principios de diferenciación independientes y jerarquizados: la oposición principal entre la producción pura, destinada a un mercado restringido a los productores, y a la gran producción, orientada a la satisfacción de las expectativas del gran público, reproduce la ruptura fundadora con el orden económico, que está en la base del campo de producción restringida; se solapa con una oposición secundaria que se establece, en el interior mismo del subcampo de (187) producción pura, entre la vanguardia y la vanguardia consagrada. 
imitadores y seguidores jóvenes, culmina con la publicación de Ritmos de Pedro Antonio González en 1895" (29-30). El segundo momento, el cual se extiende hasta el año 1907, está marcado por la ruptura en la poesía moderna, junto con la aparición de Romances de Hoy de Francisco Contreras. Por último, el cierre definitivo del Modernismo lo marca el año 1916, en el cual fallece Rubén Darío y donde aparece "Espejo de Agua" de Vicente Huidobro.

No podemos dejar de mencionar lo que sucede con las revistas literarias entre 1905 y 1912. La entrada de la revista Zig- Zag (1905) y, por consiguiente, el despliegue de la industria editorial homónima, abrió un mercado escritural y periodístico amplio y avasallador que cubrió prácticamente a todos los públicos, desde las revistas magazinescas que apuntaban a los sectores altos y otras a sectores medios, las revistas para mujeres y la familia, las publicaciones para niños y otras con contenido cómico, absorbiendo, así, tanto a autores como a lectores, lo que provocó un silencio prolongado de periódicos netamente literarios creados por productores independientes, autónomos, aunque, claramente, sin el mismo alcance mediático de Zig- Zag y compañía.

Pero no fue hasta 1910, año del Centenario y de la publicación de El Inútil de Edwards Bello, cuando la "producción pura", aquella que no tiene más público que los mismos productores, se reactivara con la Revista Contemporánea dirigida por Pedro Prado, el líder de "Los Diez", y, en 1912, con Musa Joven de la cual nos ocuparemos a continuación.

La revista Musa Joven fue la primera publicación que Vicente García-Huidobro Fernández $z^{7}$ co- fundó (su madre, doña María Luisa la fundó) y dirigió. Su primer número apareció el día 02 de junio de 1912, y en sus páginas se reúnen escritural y gráficamente elementos modernistas, como lo son los dibujos de flores y filigranas inspirados en las pinturas de tipo "mítico" y los homenajes a Rubén Darío. Dentro del listado de colaboradores estaban: Francisco Contreras, Fernando Santiván, Joaquín Edwards Bello, Martín Escobar, Hernán Díaz Arrieta (Alone), Jorge Hübner Bezanilla, Juan Guzmán Cruchaga, entre otros. Los autores mencionados, previo a su participación de esta revista, ya tenían una larga trayectoria dentro de estas publicaciones, lo que nos permite reconstruir el proceso de constitución de un campo literario de revistas. La participación de

7 Para Vicente García- Huidobro Fernández, su seudónimo más famoso, el cual perdió la capacidad de "extrañamiento", es Vicente Huidobro, alias que no parece tan novedoso, pero sin embargo encierra su conflicto con su habitus, en tanto que al reducir su apellido compuesto, lo que pretende es "disimular" su proveniencia aristocrática; es por ello que, en sus primeras revistas, el poeta juega con las siguientes firmas: Vicente García Fernández, Vicente Huidobro Fernández, Vicente G. Fernández y Vicente García F. En términos teóricos, la operación seudonimia se extiende a la posición de un sujeto en tanto a la posibilidad, dentro del campo de lucha que es el campo literario, específicamente el campo literario de revistas, para concretarse como sujeto- artista en el espacio público. Para Michel Foucault (p.337), el nombre de un autor "asegura una función clasificadora", es decir, es una construcción simbólica. Mientras que para Gerard Genette (2001), el seudónimo provoca un efecto que va a tener resultados a nivel discursivos y textuales. Tal como los seudónimos, las revistas literarias son bienes simbólicos, en tanto estratagemas de posicionamiento. 
escritores en esta revista, por otra parte, no se limitó sólo a los chilenos, pues también aparecieron en ella Ramón del Valle- Inclán, José Enrique Rodó, Eça de Queiroz, Azorín, Pío Baroja y Gabriel D’ Annunzio.

Las revistas son, para Bourdieu (2005), bienes culturales que los productores que buscan posicionarse dentro del campo crean con el objetivo de aumentar su capital simbólico. Para Jacques Dubois (1988), las revistas son instancias institucionalizadoras. En tanto que Daphne de Marneffe (2007) y Paul Aron (1998) coinciden con la idea del "efecto red" de las revistas. Para nosotros, las revistas son un capítulo constructor del campo, por cuanto estas publicaciones son activadoras del espacio literario. Además, son lugares simbólicos de "visibilización" de nuevas subjetividades, a la vez que espacios de tomas de posición de los escritores y escritoras partícipes de ellas con la intención discursiva de contravenir su habitus e influir en las reglas del campo mismo. Por lo tanto, las revistas son la "trinchera" y a la vez el almácigo de nuevas sensibilidades que mutan a medida que van escribiendo la historia de la revista misma.

Este es el caso de Musa Joven, pues los autores que en ella escribieron eran seguidores de Darío; no obstante, llevaron las rupturas del modernismo a un extremo de ironía y sarcasmo tales que deformaron la escritura tradicional, transformándola en vanguardista. Así también lo consideran Muñoz y Oelker (1993), quienes determinan como grupo de transición a "Jorge Hübner Bezanilla, Vicente Huidobro, Ángel Cruchaga Santa María, Daniel de la Vega, Tomás Chazal, Pablo de Rokha, Juan Guzmán Cruchaga y Gabriela Mistral." (156)

Dentro de los poetas nacionales que iniciaron sus publicaciones en esta revista, fue Carlos Díaz de Loyola (Pablo de Rokha), quien, en el número tres, escribió el poema "El espino", en el cual leemos los primeros "gemidos" rokhianos. El sujeto poético de De Rokha ya discute la indiferencia, discordancias y contradicciones que guarda en sí mismo. Procedemos a citar algunos versos:

El espino,

negruzco que sombrea

el áspero camino,

que conduce a la Iglesia de la aldea

es negro, es hosco, huraño,

como oscura visión de desengaño.

Entre sus ramas toscas,

de patriarca feudal,

tienen los búhos remembranzas foscas,

y ensueños negros cual traidor puñal.

[...]

Un tedio,

incurable tal vez sin remedio,

parece que agobiara

esa existencia rara, 
[...]

Se parece al poeta

bohemio, de los barrios apartados,

esa figura escueta

esa negra silueta,

con melena de espinas punzadoras,

y chambergo de mustias zarzamoras.

(Musa Joven, $\mathrm{n}^{\circ}$ 3, 1912: 09)

Ya se vislumbra la heterodoxia, la misma de la cual será precursor Huidobro y Ángel Cruchaga, pero no por estar experimentado cambios paulatinos respecto de los cánones del novecientos se van a olvidar de Darío, a quien incluso se le dedicó el número 5 de la revista, del mes de septiembre de ese mismo año.

Respecto del nicaragüense Francisco Contreras, en el editorial, escribió lo siguiente:

jJóvenes amigos! Nosotros somos poco partidarios de las autoridades, siempre tiránicas. Pero la apreciación sincera de personas cultas no puede menos de sernos respetable. Unamos pues, a tan bellas palabras en loor del maestro, nuestro aplauso entusiasta de artistas, americanos y de jóvenes. (Musa Joven, n 5 , 1912: 02)

En tanto que Vicente García Fernández expuso lo siguiente:

¡Tan alto es para mí el concepto de genio! Y el genio de Rubén Darío creo que ya nadie lo discute. Sí, lo discuten algunos todavía, y si no fuera así no sería genio.

[...] Rubén Darío alumbró ese obscuro misterio. El idioma en sus labios adquiere una faz nueva y él nos muestra horizontes ignorados.

La característica de Rubén Darío es la individualidad, la personalidad; ya él lo dijo: <<mi poesía es mía en mí>>. La obra de Darío es grande porque es sincera $\mathrm{y}<<$ ser sincero es ser potente $>$. (Musa Joven, $\mathrm{n}^{\circ}$ 5, 1912: 05).

De esta cita que tomamos, se desprenden dos asuntos. El primero de ellos es la reafirmación de Darío en tanto epicentro de estructuración de la sensibilidad modernista, donde por medio de su poesía aspira a lo armonioso, a lo novedoso y a la exaltación del uno por sobre las demás escrituras del momento. En un segundo lugar, es interesante leer este comentario como si se tratase del propio programa creador o despliegue inicial de los principios estéticos huidobrianos. En definitiva, entre-leemos una voluntad de acción cuyos aspectos centrales son el cuestionamiento y el impulso por reinventarse. Sobre esto mismo, mediante Musa Joven, se evidencia con mayor notoriedad el tránsito modernista- vanguardista de Vicente Huidobro, pues en el último número de esta publicación (número 6 del mes de octubre de 1912), él divulgó el caligrama conformado por dos triángulos equiláteros llamado "Japonerías de estío". Si 
bien el título resulta modernista, en tanto que recuerda a las famosas sonatas de Valle-Inclán (Sonata de primavera, Sonata de estío, etc.), y porque alude a una típica característica del exotismo modernista, la forma, la disposición de los versos la transforma en dos pagodas legibles, entendibles e interpretables desde diferentes ángulos del "dibujo".

Las polémicas, por otra parte, no podían estar ausentes. Tal como le sucedió a Edwards y El Pololo, a Musa Joven la "acosó" el diario radical La Razón, situación que La Dirección de la revista enfrentó en el editorial de su número 6, el que procedemos a citar:

"Musa Joven" Condecorada

Hemos sabido que el casi diario radical $<<$ La Razón $>>^{8}$ ha tenido términos insultantes para nuestra Revista. Gracias, señores de $<<\mathrm{La}$ Razón>>.

¡Nosotros que nunca nos habíamos ocupado de ellos!

Cierto que los chicos siempre conocen a los grandes, pasando, ellos, desapercibidos entre la turbamulta.

Con tanta razón obra siempre <<La Razón $>>$ que, su ex director don Ángel C. Espejo, que era el único de verdadero valer de ese casidiario, hubo de retirarse... porque se ahogaba entre tanta arenilla. Hay gente que, cuando insulta, honra, y cuyo aplauso es un insulto. Por eso nuestra Revista levanta la frente con más orgullo que nunca.

Musa Joven se presenta a sus lectores condecorada.

LA DIRECCIÓN

(Musa Joven, $\mathrm{n}^{\circ}$ 6, 1912: 01)

Para la gracia de La Razón y la desgracia del grupo de Musa Joven, el número 6 fue su última aparición. No obstante ello, y reagrupados bajo un nombre dariano y con el epígrafe de "Revista Quincenal Libre", abrió sus páginas a los lectores la revista Azul el 15 de septiembre de 1913, bajo la dirección de Vicente Huidobro y Carlos Díaz Loyola (Pablo de Rokha), la que tuvo sólo 3 números.

La revista Azul marcó con mayor notoriedad la des-construcción del habitus de Huidobro, pues esta publicación tuvo tintes sociales, evidenciables por la cercanía que este medio tuvo con los estudiantes universitarios, provenientes, en su mayoría, de las clases mesocráticas. Es decir, la pulsión vanguardista otorgará un nuevo barniz en su escritura, de donde destacaremos parte del poema "El Gran Pujista", aparecido en el número 1 de esta revista:

8 El diario La Razón era la publicación del Partido Radical y, en este mismo año, específicamente el 1 de noviembre de 1912, habían polemizado en un artículo sobre la Federación de Estudiantes de Chile, donde se refieren a la labor social de la entidad y a sus múltiples vínculos con obreros y artesanos, "hoy en día todos ellos constituyen la gran amenaza para los monopolizadores de la moral y los conductores insolentes de conciencias ajenas". (Ct. en Subercaseaux, 2004: 105.) 


\section{El Gran Pujista}

(Al que espiritualmente se sienta aludido)

El Gran Pujista es un individuo universal. Pertenece a la casta de los parvenu y para buscar su genealogía, mejor dicho la etimología de su nombre hay que remontarse a los pujadores. ¡Arribistas estúpidos que babean ante las multitudes por un aplauso!

El Gran Pujista penetra en las imprentas de rodillas y tiene la vara de mimbre de su espinazo, hecha un arco en fuerza de doblarse.

Los Hombres cuando lo ven sienten cómo la saliva se agolpa entre los dientes y se prepara el escupo. [...]

El Gran Pujista duerme bajo la Envidia en el jergón de la Hipocresía. Come Odio y bebe Calumnia...rumia Odio y Calumnia.

[...]

Rufián! Eunuco mental. Intrigante!

El Gran Pujista busca primero la Lisonja.

Después esgrime la Mentira y dispara el Anónimo sordamente [...]

El Gran Pujista morirá pujando por subir. Confiará su triunfo a las sonrisas cortesanas [...]

El Gran Pujista entrará a las imprentas hecho un ovillo y publicará arículos elogiosísimos a su persona escritos por él mismo. [...]

El Gran Pujista es el más alto representante del rastacuerismo y de la miopez intelectual. [...]

El Gran Pujista es una mezcla de Yago, Tigelino, Polonio... Tomate, Cebolla y Ají. [...]

Vicente García H. FERNÁNDEZ

(Azul, $\left.n^{\circ} 1,1913: 14-16\right)$

De acuerdo a lo leído, este poema ya no es representante del modernismo, es atrevido y, sobre todo, se cuestiona el intelecto del artista. Aquí está ese lenguaje soez que recurre al ruido, al garabato, las paradojas y la ironía, pues la obra se hace abierta. En este sentido, la revista es una obra abierta, nace con una data de muerte próxima pues no pretende ser un "músculo colgante de museo", sino que un texto total, que niegue todo y a todos, inclusive a sí misma, por eso no perdurará mucho más. En definitiva, tanto en este poema como en la revista completa, siguiendo a Bernardo Subercaseaux (2004), "se encuentra presente una idea clave [...] en el espíritu de vanguardia. Se trata de la idea de concordancia y paralelismo entre los distintos órdenes de la realidad; entre la vida del espíritu (la inteligencia, la imaginación, la creación) y la vida del cuerpo (la técnica, la ciencia, el movimiento social y la realidad material)".

En Azul número 3, Vicente García Huidobro Fernández, tal como firma este artículo, entra al ruedo crítico, cuestionando directamente a aquellos agentes 
que están ejerciendo el poder dentro del campo literario, como lo son Rojas Segovia y Omer Emeth, demostrando una vez más el afán por contradecir lo anterior; citamos parte de este artículo:

Es tiempo ya de que los jóvenes vayan demoliendo uno por uno a esa caterva de fantoches de que está plagada nuestra literatura. Hay algunos de estos señores que se sienten con el derecho de dogmatizar y pontificar desde las columnas de algún diario sobre cuestiones literarias que más les valiera callar para no dar prueba semanal de heroica ignorancia.

Es tiempo ya que los jóvenes vayan viendo y observando las ridículas arbitrariedades de la crítica del señor Omer Emeth. Tengo la seguridad de que ningún ser pensante de esta tierra, toma en cuenta la opinión semanal del señor Omer Emeth, pero a pesar de todo este buen capellán de la literatura sigue teniendo su tribuna en $<<$ El Mercurio $>>$ que es un diario serio. [...] El señor Omer Emeth estaría bien como confesor de los artistas, absolviéndolos de tantos y tantos pecadillos sensuales como cometen esos deliciosos y parisinos muchachos, pero no como árbitro de cuestiones de arte [...]

(Azul, no 3, 1913: 16-18)

Mediante esta crítica y nueva escritura que Huidobro está construyendo en 1913, ya se vislumbra al fundador de un nuevo "nomos específico", pues, al cuestionar a un crítico canónico, autorizado, y portador del capital simbólico, a la vez que partícipe de los medios periodísticos del poder y con llegada al gran público, está instalando las primeras luces hacia una revolución simbólica de la cual Vicente, como nomoteta, está dispuesto a encabezar.

Con todo, el camino estético e ideológico que ya tiene Huidobro, así también con su autoafirmación nomotética, se comprende mejor el trayecto que siguió hasta el 1914 donde dictó la conferencia «Non serviam» en el Ateneo de Santiago, planteamiento fundamental en su credo estético.

\section{Ni tristes ni contentos}

Otra autora que por estos mismos años estaba configurándose como sujeto escritora, era Teresa Wilms, quien ya estaba casada con Gustavo Balmaceda, y se encontraban viviendo en Iquique en el hotel "Phoenix", ciudad donde ella empezó a relacionarse con literatos y políticos ligados al anarquismo, particularmente con Víctor Domingo Silva, quien además participaba, esporádicamente, de las publicaciones de Huidobro, en tanto que ella ya enviaba sus primeros textos a los medios de prensa local bajo el seudónimo "Tebal".

9 Citando a Bourdieu (2005), "en la fase crítica de la constitución de un campo autónomo que reivindique el derecho a definir él mismo los principios de su legitimidad, las contribuciones al cuestionamiento de las instituciones literarias y artísticas [... ] y a la invención y la imposición de un nuevo nomos" (99). 
Pero el evento más interesante y relevante, respecto de la construcción del habitus de Wilms, fue la visita de la feminista española Belén de Sárraga ${ }^{10}$ al norte salitrero, quien se hospedó en el mismo hotel de la poeta y que, como plantean Antivilo y Vitale (1999), "de seguro las dos mujeres se encontraron en el vestíbulo o en el paseo, -teniendo en cuenta además que Víctor Domingo Silva, el poeta que en ese mismo año participaba dentro del comando político de Arturo Alessandri Palma ("El León de Tarapacá" como el escritor lo re- bautizó) eran compañeros de tertulias de Teresa Wilms y, a la vez, se congregaba en la sede "El Despertar de los Trabajadores", donde la española dictó conferencias."(17) Paradójicamente, uno de los máximos opositores a la presencia de la feminista en el puerto nortino fue Gustavo Balmaceda, quien difundió en la prensa iquiqueña sus críticas contra la española, tildándola de "conferenciante jacobina." La anarquista española influyó en la conciencia de la poeta, quien pronto dio tantas muestras de rebeldía, las que pagó con el enclaustramiento.

La cinematográfica escapada de Teresa desde el convento La Preciosa Sangre de Santiago centro, fue organizada y apoyada por Huidobro, con quien en 1916 y a los 23 años de edad arribó a Buenos Aires, Argentina. A su llegada, el mismo Vicente la introdujo en el medio literario porteño, pues él mantenía correspondencia con Alfredo Bianchi, el editor de la revista Nosotros, donde Wilms Montt inició sus apariciones públicas.

Con respecto al autor de Altazor, él aprovechó este viaje para pronunciar una conferencia sobre la poesía en el Ateneo, donde esbozó su teoría creacionista. A ella asistieron Leopoldo Lugones y José Ingenieros. Además, allá mismo publicó Espejo de Agua.

La revista Nosotros, en tanto, la cual se publicó entre los años 1908 y 1943 (con una breve interrupción entre 1934 y 1936), era editada por Alfredo Bianchi y Roberto Giusti, quienes, además de tener la revista, realizaban publicaciones bajo el mismo sello editorial. Es en esta instancia donde, en 1917, Wilms Montt editó Inquietudes Sentimentales, el que fue anunciado y criticado por Arturo Lagorio con las siguientes palabras:

10 Belén de Sárraga visitó Chile por primera vez el año 1913, fecha en la cual se produjo una auténtica explosión de agrupaciones feministas, sobre todo, en el Norte Grande, la región de Tarapacá. Luis Emilio Recabarren, el fundador del Partido Obrero Socialista en Chile y del periódico El Despertar de los Trabajadores, fue quien invitó al país a la conferenciante española, debido a que previo a la visita de la feminista ibera él había impulsado la organización de los primeros centros de mujeres trabajadoras y de esposas de obreros. La presencia de la andaluza provocó gran revuelo dentro de los grupos conservadores del país, según indican Luis Vitale y Julia Antivilo, debido a que las ideas de doña Belén "se encontraban atravesadas por el obrerismo, republicanismo, federalismo, antimilitarismo y el anticlericalismo. Por lo demás, ella concebía al feminismo como un movimiento social que tenía como utopía lograr una sociedad realmente justa e igualitaria." (Antivilo, Vitale, 1999, p.13). En su segundo viaje a Chile, en 1915, la situación había cambiado: los radicales, cada vez más comprometidos con el sistema político, han abandonado sus posturas anticlericales. De los ideales de Balmaceda ya no queda nada. La recepción de De Sárraga fue mucho menos efusiva que en 1913 y sólo quedaba la lealtad y el entusiasmo de los anarquistas. 
La señorita Thérése Wilms intenta hacer lo mismo, pero carece de la triste ironía del otro, que lejos de llorar sus penas se ríe de ellas [refiriéndose a Charles Baudelaire]. Esta lagrimea a veces y acaso sea su mejor condición, porque nos muestra su débil feminilidad, que es la expresión más sincera del espíritu delicado.

[...]

Inquietudes Sentimentales juzgado sin severidad y encuadrado en los términos del prólogo [...] es un libro interesante que se lee con agrado.

Completan el libro, brillantemente presentado, varias ilustraciones del habilísimo dibujante López Naguil.

(Nosotros, no 100: s/p)

La crítica con tintes patriarcalistas es patente, y si bien los comentarios no son positivos ni menos la destacan como sujeto artista, vale la pena aclarar que, al menos en Buenos Aires, sí pudo publicar e ingresar de lleno a las redes de artistas agrupados bajo este sello, sobre todo en esta revista y bajo esta editorial, ya que, recién en 1918, cuando ella ya estaba en Madrid y con dos publicaciones más (En la quietud del mármol y Anuarí), apareció en Nosotros una selección de versos de la poeta argentina Alfonsina Storni, de la uruguaya Luisa Luisi y la chilena Gabriela Mistral.

En 1919, ya estaban instalados en Europa los tres autores en que se centra este artículo, siendo Madrid epicentro de los acontecimientos literarios y de la bohemia de los hombres del '98 como Ramón del Valle-Inclán, los hermanos Machado, Ramón Gómez de la Serna, entre otros, y donde Joaquín Edwards Bello se conoció con Teresa Wilms, en el café "El gato negro", también frecuentado por el novelista chileno Augusto D’ Halmar. Sobre estos encuentros y la presencia de la poeta, el cronista comentó lo siguiente: "Ella representaba una gran camarada. La consideraba como una amiga, nada más. Ella en Madrid dio una nota aparte de desenvoltura y elegancias novísimas." (Edwards, 1924: 195).

Pero la estadía de Joaquín Edwards Bello en Madrid era intermitente, pues, en ese mismo año (1919), viajó a París donde fue proclamado presidente DADA por Tristán Tzará, en tanto que Huidobro, también en la ciudad de la Tour Eiffel, estaba trazando las primeras líneas del "Viajero en Paracaídas", es decir, el Altazor. En el año 1920, Teresa los alcanzó en la ciudad donde ella fallecería para la navidad de 1921, situación que no dejó indiferentes ni a Joaquín ni a Vicente. El primero de ellos dijo: "Ella era como el agua de una fuente que no ha sido desflorada por la luz del día." (Ct. en González, O.: 64), mientras que el poeta la recordó con las siguientes palabras: "ella es la mujer más grande que ha producido la América. Perfecta de cara, perfecta de cuerpo, perfecta de elegancia, perfecta de inteligencia, perfecta de fuerza espiritual, perfecta de gracia." (Ct. En Nómez, N., 2000a: 404) 


\section{Conclusiones}

La segunda década del siglo XX estuvo marcada por las inestabilidades del campo de poder, del campo literario y, por ende, de los sujetos que pugnan posiciones dentro de este. Nos centramos en este período, pues es una de las décadas más inquietantes respecto de la autonomización del campo de revistas, ya que es en estas publicaciones donde tomamos el pulso de las construcciones de espacios alternativos para la inclusión de nuevos saberes dentro de la institución literaria.

Debido a lo recién reseñado, es que nos interesó revisar los casos de Joaquín Edwards Bello y Vicente Huidobro, especialmente, a través de las revistas, ya que es por medio de estas instancias constructoras del campo literario donde ambos sujetos discursivos se dejan aprehender para intentar comprender las posiciones que ambos disputaron durante la primera parte del siglo XX. En este sentido, destacamos que, mientras Edwards Bello discute contra la sociedad conservadora y los medios de comunicación que descienden desde el campo de poder; Huidobro, en tanto, se instala contrario a los agentes continuadores y propiciadores de la institución literaria canonizada en pos de alcanzar mayor autonomización para el campo literario. Es por esto que hemos incluimos, dentro del desarrollo del trabajo, algunos textos literarios de los poetas que se agruparon tras las primeras revistas de Huidobro, pues en ellas leemos el dinamismo escritural y la movilidad de agentes.

La inclusión de Teresa Wilms Montt dentro de esta revisión se debió a nuestro interés por rearticularla dentro del grupo de escritores que trastocaron su habitus; así también para destacar su presencia dentro del medio literario bonaerense, donde publicó sus primeros libros. Su participación en el grupo editorial de la revista Nosotros, en tanto, sirvió de antecedente para el ingreso de otras escritoras dentro de este mismo medio, como fue el caso de Alfonsina Storni y Gabriela Mistral. Es importante subrayar que la relación escritural con esta publicación no terminó cuando Wilms Montt se mudó a Europa, ya que, tanto desde España como Francia, ella fue corresponsal.

Por último, el cierre de estas dos primeras décadas significó el quiebre con el sistema aristocrático y oligarca, espacio social desde donde provenían los autores revisados y que, por medio de su escritura y de las estrategias que desplegaron, fue posible dar cuenta de los quiebres y contradicciones.

\section{Bibliografía}

\section{Corpus Primario}

La Juventud (1901), nº 1, Marzo, Valparaíso. Chile. (1901), n² 2, Marzo, Valparaíso, Chile. 
Ni aristócratas, ni rebeldes, ni tristes ni contentos / Dra. (C) Marina d. A. Alvarado

(1901), nº 5, Diciembre, Valparaíso, Chile.

El Pololo (1902), nº 3, Noviembre, Valparaíso, Chile.

Musa Joven (1912), nº 1- n 6, Santiago, Chile.

Azul (1913), n 1- n 3, Santiago, Chile.

Nosotros (1918), n 100, Agosto, Buenos Aires, Argentina.

\section{Corpus Crítico}

Alvarado, M. (2005). Construcciones discursivas y estrategias textuales en Teresa Wilms Montt: Contradicciones y autofiguraciones de una sujeto de principios del siglo XX. Tesis para optar al grado de Licenciado en Educación en Castellano, USACH.

Antivilo, J. y Vitale, L. (1999). Belén de Sárraga: Precursora del feminismo hispanoamericano. Santiago de Chile: Ediciones CESOC.

Bourdieu, P. (1989). "El campo literario. Prerrequisitos críticos y principios de método". En Criterios, La Habana, no 25- 28, 20- 42.

(2005). Las reglas del arte. Génesis y estructura del campo literario. Barcelona: Editorial Anagrama.

Edwards Bello, J. (1922), Carta 1922. Manuscrito no publicado. Fundación Vicente Huidobro.

(1924). Crónicas. Santiago de Chile: Talleres "La Nación".

Foucault, M. (1999). “¿Qué es un autor?”. En Entre Filosofía y Literatura, Barcelona: Paidós.

Genette, G. (2001). Umbrales, México D.F.: Siglo XXI.

Oscar González Campos. "Para que no te olviden Teresa Wilms", en Revista Vida Médica, $n^{\circ} 4$.

Hübner, S. (1993). "Una hora de charla con Teresa Wilms Montt". En Revista Universitaria, $\mathrm{n}^{\circ} 41$, pp. 54- 58 .

Marneffe, D. (2007). Entre modernisme et avant-garde. Le réseau des revues littéraires de l'immédiat après-guerre en Belgique (1919-1922). Tesis para optar al grado de Doctor en Lenguas y Letras. Universidad de Liège.

Muñoz G., L. y D. Oelker. (1993). Diccionario de movimientos y grupos literarios chilenos. Concepción: Ediciones Universidad de Concepción.

Nómez, N. (1996). Antología Crítica de la Poesía Chilena. Tomo I. Santiago de Chile: Lom.

(2000). Antología Crítica de la Poesía Chilena. Tomo II. Santiago de Chile: Lom.

Subercaseaux, B. (2004). Historia de las Ideas y de la Cultura en Chile. El Centenario y las Vanguardias. Tomo III. Santiago de Chile: Editorial Universitaria. 